\title{
O passo atrás de Lucrecia: Disputas discursivas entre filmes e séries
}

\author{
Lucrecia's step back:
} Discursive disputes between films and TV series

\author{
MARCEL VIETRA BARRETO SILVAa \\ Universidade Federal da Paraíba, Programa de Pós-graduação em Comunicação. \\ João Pessoa - PB, Brasil
}

\section{RESUMO}

O objetivo deste artigo é analisar as disputas discursivas que permeiam o debate comparativo entre filmes e séries no contexto da crítica cultural contemporânea. Partimos dos argumentos da diretora Lucrecia Martel contra as séries televisivas para compreender, diacronicamente, as tensões históricas entre cinema e televisão e a sua perenidade no cenário atual. Para isso, proporemos aqui três eixos dominantes na avaliação comparativa: experiência espectatorial, estilo e narrativa. Com isso, vamos problematizar os argumentos da superioridade apriorística do filme em relação às séries, sem perder do horizonte a natureza distintiva da disputa simbólica em curso.

Palavras-chave: Ficção seriada, filme, cinema e televisão, disputas discursivas, crítica cultural

\begin{abstract}
This paper intends to analyze the discursive disputes that permeate the comparative debate between films and TV series in the contemporary cultural criticism. We take from the arguments of Argentinean filmmaker Lucrecia Martel against TV series in order to understand, diachronically, the historical tensions between cinema and television and its perpetuity in the current scenario. To do so, we come up here with three dominant axis in the comparative evaluation: espectatorial experience, style and narrative. With this, we aim to discuss the arguments of an aprioristic superiority of film over TV series, without forgetting the distinctive nature of this ongoing symbolic dispute.
\end{abstract}

Keywords: Serial fiction, film, cinema and television, discursive disputes, cultural criticism 


\section{INTRODUÇÃO}

EDIÇÃO DE NÚMERO 44 da revista francesa CinémAction, editada
por Guy Hennebelle e René Prédal, traz um longo dossiê intitulado "A
Influência da Televisão no Cinema" (1987). Aquele era um momento singular da presença do cinema na televisão europeia, e sobretudo francesa, devido à crescente queda na venda de bilhetes em salas comerciais, somada à necessidade de regulamentação da distribuição para cinema e televisão, refletindo-se numa legislação hoje paradigmática no respeito ao tempo das janelas de exibição - o imbróglio entre o Festival de Cannes e a Netflix, ocorrido na edição de 2017, acerca da programação de filmes da plataforma nas telas do festival, é bastante sintomático da complexidade das relações políticas e econômicas no que se refere à distribuição de filmes no cenário europeu (Fresco, 2019; Lobato, 2019).

Voltando à França dos anos de 1980, o país havia acabado de aprovar a Lei 86-1067, de 30 de setembro de 1986, voltada para a garantia da liberdade de imprensa e para a regulação dos meios de produção e distribuição audiovisual, a fim de assegurar o equilíbrio econômico entre os agentes do setor, que seria acompanhado pelo Conselho Nacional de Cinema (CNC). Uma das questões centrais, e bastante debatida na edição da CinémAction supracitada, era a necessidade de preservar a exploração econômica dos filmes nas diferentes janelas disponíveis à época (salas de cinema, videocassete, televisão paga e televisão aberta), bem como inserir os atores interessados na distribuição desses filmes no próprio processo de fomento, através da contribuição das empresas de televisão aos fundos de produção. Gilbert Gregorie (1987), presidente da Federação Nacional de Distribuidoras de Filmes, escreve num dos artigos da revista que, à época, "a audiência de um filme francês se fazia $96 \%$ na televisão e apenas $4 \%$ na sala de cinema” (p. 41). Nesse sentido, para além das questões estéticas e culturais prementes no debate, Gregorie explica que o modelo de negócio do cinema, tal como se moldou a partir ali nos anos 1980, só era capaz de existir por causa da televisão.

Essa centralidade econômica na relação entre televisão e cinema, além da própria natureza intermidiática dos meios audiovisuais, nunca foi, na prática, uma questão bem resolvida. A crítica de cinema, os realizadores, os festivais e a academia, cada qual a seu modo, contribuem ainda hoje para enfatizar, entre cinema e televisão, mais as cisões que as separam que as pontes que as conectam. Um exemplo interessante para ilustrar, no contexto brasileiro, a separação das pesquisas em cinema e televisão é o encontro da Sociedade Brasileira de Estudos de Cinema e Audiovisual (Socine). Embora a Socine (s.d.) tenha como primeiro objetivo, tal como consta no seu Estatuto, artigo 2, “a) aglutinar, sistematizar e 
divulgar experiências relativas ao estudo da imagem em movimento, em seus diferentes suportes, e áreas afins", seus encontros são ocupados, em sua mais larga proporção, por pesquisas de cinema tout court, para as quais o audiovisual - e a televisão, acima de tudo - é um apêndice circunstancial, uma salvaguarda às inconstâncias do exclusivismo.

Através de uma pesquisa nos cadernos de resumo dos quatro últimos encontros ${ }^{1}$, vimos que o termo televisão aparece, em títulos de trabalhos e resumos, da seguinte maneira: em 2016, o termo surge quatorze vezes; em 2017, aparece dez vezes; em 2018, é mencionado oito vezes; e, por fim, em 2019, apenas três vezes. Para termos um comparativo, a palavra cinema aparece, em 2016, 730 vezes; em 2017, 664 vezes; em 2018, 647 vezes; e, em 2019, 694 vezes $^{2}$.

No presente trabalho, não nos cabe determinar as razões, de ordem política, cultural e sobretudo epistemológica, que justificam tal descompasso. Nem se configura nosso propósito requerer qualquer tipo de atenção determinada, como se as pesquisas em televisão carecessem de uma cota de tela nos encontros da Socine - há outros fóruns, em diferentes organismos e sociedades de pesquisa, que sobrevivem frutiferamente nas suas singularidades. O que nos interessa, portanto, é compreender, nos termos de hoje, a natureza discursiva das disputas entre filmes e séries, e entre cinema e televisão, no debate contemporâneo, para que uma crítica do audiovisual possa também ter no seu horizonte a complexidade da relação entre os meios, suas conexões e seus descompassos, sem cair apenas em suas distinções culturais.

O ponto de partida, que surge no título deste trabalho, veio da chamada de matéria contendo uma entrevista da diretora argentina Lucrecia Martel, para o periódico portenho Perfil, na ocasião de lançamento de Zama, seu mais recente filme: "Las Series Son un Paso Atrás" (Domínguez, 2018), estampa a matéria, num claro desejo de uma declaração polêmica da renomada diretora, a fim de obter os famosos cliques. No entanto, ao pesquisar outras entrevistas de Lucrecia Martel, as suas diatribes contra a televisão, os serviços de vídeo sob demanda e, sobretudo, as séries televisivas, continuaram uma constante, tornando evidente o interesse de iluminar um debate que muitos julgavam ultrapassado: as séries de TV, tão proeminentes enquanto fenômeno sócio-histórico da contemporaneidade, com sua lógica de exibição doméstica, altamente serializada, de distribuição mundial, com a recomendação muitas vezes definida por algoritmos e estimulada ao consumo excessivo, seria, nas palavras da diretora, um "passo atrás na linguagem audiovisual”. Estamos, afinal, numa cultura das séries (Silva, 2014), um momento singular e altamente globalizado de produção, circulação e consumo de obras audiovisuais seriadas. As falas de Martel, portanto, serviram para trazer novamente ao primeiro plano do debate as disputas simbólicas entre
${ }^{1}$ Devido à pandemia da

Covid-19, o Encontro anual da Socine foi cancelado em 2020.

${ }^{2}$ Informações colhidas do site da Socine: https://bit.ly/3paFZrO. 


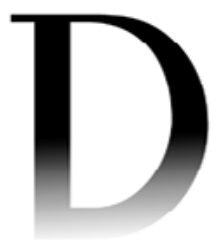

${ }^{3}$ No original: "both close analysis of this interconnection and an understanding of the processes of exchange and transformation which occur as films move between the two media". Esta e demais traduções, do autor. cinema e televisão que, pelo menos desde o pós-guerra, ilustram a complexa tensão cultural, econômica e política que atravessa os campos.

Ao analisar a literatura sobre a interface entre cinema e televisão, duas perspectivas se impuseram como dominantes: de um lado, temos uma larga tradição de pesquisas, de viés sócio-histórico, que investiga as relações entre os meios a partir das articulações entre os agentes institucionais (canais, estúdios, produtoras), as instâncias criativas (dramaturgos, diretores, encenadores) e as esferas públicas de circulação e recepção. Trabalhos como os de Hannah Andrews (2014), sobre as convergências e divergências entre cinema e televisão na Inglaterra a partir dos anos 1990, e de Lucy Mazdon (1999), que investiga a presença do cinema na televisão britânica, investem nessa abordagem para enfatizar a inquestionável relação próxima entre as mídias, vista muitas vezes com demérito pela crítica. Essa depreciação costuma interditar, como argumenta a autora, "tanto a análise detida desta interconexão quanto a compreensão dos processos de trocas e transformações que ocorrem quando os filmes transitam entre as duas mídias"3 (p. 72).

De um ponto de vista nacional, uma matriz inescapável para compreender as articulações entre cinema e televisão é Renato Ortiz (1995), por seu interesse em investigar a formação cultural do país observando como tanto o cinema quanto a televisão historicamente tensionaram as posições subsumidas da cultura popular, da cultura erudita e da cultura de massas, criando atravessamentos e rearranjos específicos para a construção de ideias de identidade nacional e de cultura brasileira. Esse tensionamento é notório na própria formação das condições industriais para a produção cinematográfica no comparativo com as dinâmicas particulares de consolidação infraestrutural e econômica da televisão, durante as primeiras décadas dessa mídia no país. Ainda nessa linha, uma referência importante são os trabalhos que analisam o histórico de tensões entre cinema e televisão no Brasil (Bahia, 2014; Bahia \& Amancio, 2010), aprofundando ainda a necessidade de uma compreensão menos enviesada das disputas comparativas entre os meios.

De outro lado, temos a perspectiva que se interessa pelo estudo da linguagem, investigando as possibilidades expressivas dos meios, suas estratégias de endereçamento de signos, seus enquadramentos, suas sonoridades, a textura sensível das próprias imagens. Aqui, as abordagens podem variar a partir de interesses específicos que vão desde as construções narrativas e ficcionais (Balogh, 2002; Butler, 2018; Machado, 2014; Smith, 2018), a ontologia das imagens cinematográficas e videográficas (Caldwell, 1995; Hart, 2004; Machado, 1997) e as conformações em gêneros e formatos (Edgerton \& Rose, 2005; Mittell, 2004). 
No entanto, para além de uma tentativa de esgotar as referências numa síntese retrospectiva, o que nos interessa aqui é compreender a natureza distintiva desse debate (Bourdieu, 1996, 2007; Newman \& Levine, 2012), observando como, transversalmente, as tensões entre cinema e televisão se revelam no atravessamento de diferentes dimensões analíticas. Assim, para o que nos cabe neste artigo, vamos sistematizar três eixos que alicerçam os argumentos historicamente mais utilizados para depreciar as séries no comparativo com os filmes: experiência espectatorial, estilo e narrativa.

Essas três categorias não excluem a presença de outras lógicas discursivas como questões de práticas de produção e recepção - e, quando pensadas de modo articulado, podem aprofundar nossa visão dos conflitos que atravessam a crítica cultural, sobretudo num momento em que grandes serviços de streaming nativos da internet reconfiguram o mercado global, diante das urgências de isolamento social e fechamento das salas de cinema ocasionadas pela pandemia da Covid-19. Portanto, para além das rusgas históricas e das disputas econômicas, compreender a indissociabilidade dos laços que unem televisão e cinema parece, como pretendemos apontar aqui, um caminho inescapável para o entendimento da cultura audiovisual na contemporaneidade.

\section{EXPERIÊNCIA ESPECTATORIAL: GAZE, GLANCE E AS TECNOLOGIAS DA IMERSÃO}

Durante o lançamento de Bacurau (Mendonça Filho \& Dorneles, 2019), a equipe do filme fez circular nas redes sociais um curioso informativo: as salas de exibição em que a obra seria lançada deveriam aumentar em um ponto $(+1)$ o volume do som, para que a sensação provocada pelas trocas de tiros no filme fosse capaz de imergir o espectador na cena. Essa determinação técnica, que visava a agudizar a experiência do público com o engajamento sensório do filme, remete bastante à imbricação inevitável entre a natureza discursiva/narrativa do filme e o seu modelo de exibição pública. Autores como Jacques Aumont (2011) e Fernão Ramos (2016) endossam essa vinculação, destacando os modos como o cinema expandido/instalativo, por reconfigurar a relação do espectador com as imagens/sons em movimento, não mais circunscreve o campo conceitual a que se deu, desde o início, o nome de cinema.

Não se trata de estabelecer uma cadeia valorativa entre diferentes formas de expressão artística com imagens moventes e sons. Nem o cinema é igual ao universo das artes que lidam com imagens que se movem, nem o universo das artes com imagens moventes e sons a ele se restringe. Alguns desenvolvimentos em 
${ }^{4}$ No original: "El juicio negativo sobre la repetitividad es fruto de la ideología, es decir, de un juicio negativo sobre la primera acepción, la de la producción de serie, que recae también sobre el producto de serie. Y como del producto de serie forman también parte las características de su peculiar estructura interna y de una estructura de la fruición, el juicio negativo se traslada automáticamente también a éstas. Inadecuada, en fin, porque la idea preconcebida de valor impide reconocer en algunos productos contemporáneos el nacimiento de una nueva estética (o el renacimiento de una vieja estética, igual da); precisamente, una estética de la repetición". torno do conceito de "cinema expandido" fazem equivaler cinema e o conjunto das imagens em movimento em dispositivos diversos, com prejuízo para ambos os lados. (Ramos, 2016, p. 39)

Dessa forma, o dispositivo de imersão ininterrupta do espectador dentro de uma arquitetura de sala que orienta olhar e ouvidos atentos para o filme projetado, comum ao cinema, constitui uma das marcas - senão a mais reconhecida - da sua experiência espectatorial. Os aspectos sociais, econômicos e políticos relacionados a essa atividade sempre estiveram no cerne de sua valoração enquanto prática cultural, estruturando assim toda uma cadeia produtiva que pensa a sala de cinema como primeira (e principal) janela de exibição do filme comercial. Além disso, a ênfase na questão da experiência espectatorial como marcador de distinção em relação à tevê, com sua exibição em aparelhos domésticos, aberta às distrações e à dispersão, representa um atributo valorativo à atenção exclusiva que, muitas vezes, fala mais do horizonte estético no qual se insere a crítica, que da experiência perceptiva na relação com as imagens e os sons.

Nos bastasse isso, a crítica para a serialidade agudiza a lógica de distinção entre os meios. Já nos anos 1980, Omar Calabrese (1984) chamava a atenção para o conjunto de pressupostos que, historicamente, recortaram o interesse do debate estético para as obras únicas, fechadas, de experiência imersiva. Para dar um passo além disso - e, assim, compreender melhor as dinâmicas serializadas de produção, circulação e consumo audiovisual no seio da cultura de massas - ele critica diretamente esses pressupostos e propõe, ao cabo, a ideia de uma estética da repetição:

O julgamento negativo sobre a repetitividade é fruto da ideologia, ou seja, de um julgamento negativo sobre a primeira acepção, a da produção em série, que também recai sobre o produto seriado. E como a esse produto pertencem também as características de sua estrutura interna peculiar e de uma estrutura de fruição, o julgamento negativo se volta automaticamente para elas. Isso é inadequado, por fim, pois a ideia preconcebida de um valor estético unitário impede de reconhecer em alguns produtos contemporâneos o nascimento de uma nova estética (ou o renascimento de uma estética antiga, semelhante a ela); precisamente, uma estética da repetição ${ }^{4}$. (Calabrese, 1984, p. 72)

Não bastasse isso, Milly Buonanno (2008) lembra um importante histórico: em sua gênese, a televisão não se configurou como um meio ontologicamente doméstico, tendo as suas primeiras exibições ocorrido em espaços públicos 
(bares, igrejas, centros comerciais, praças, museus etc.), onde ainda hoje os aparelhos televisivos permanecem. No entanto, a televisão foi gradativamente sendo domesticada, a partir de um processo cultural mobilizado, durante os anos 1950, pela crescente organização das empresas de broadcast, pelo desenvolvimento técnico de estruturas de transmissão e recepção, e, por fim, pelo interesse das indústrias de bens de consumo em ampliar a publicidade e, consequentemente, o consumo de seus produtos.

$\mathrm{Na}$ realidade, a televisão nunca se tornou completamente um meio domesticado, ou um objeto material totalmente doméstico e domesticado, muito embora uma afirmação como essa se choque com o senso comum (incluindo aí o senso comum cientificamente creditado). Não apenas porque sua presença, ainda que tenha se tornado parte da geografia dos espaços habitados, continua a causar alarme, desconfiança e a vigilância mantida em relação àquilo que sabemos não ser totalmente confiável (e, novamente, nada disso ocorre com geladeiras ou máquinas de lavar louça); mas também porque o aparelho televisivo e suas telas nunca abandonaram de fato os espaços públicos que originalmente ocupavam; ao invés disso, a televisão continuou a se espalhar exponencialmente em áreas externas ao lar durante e após a fase de sua domesticação ${ }^{5}$. (Buonanno, 2008, pp. 16-17)

Domesticar a televisão, nesse sentido, implicava não apenas levar o aparelho televisivo para dentro das casas, mas também organizar a programação em termos de hábitos familiares específicos - numa grade, portanto - e formatar os seus conteúdos de acordo com as determinantes políticas, econômicas e culturais que essa domesticação pressupunha. Isso incluiu, claro, a domesticação dos próprios filmes, que passaram, num primeiro momento, a ocupar as grades de programação através de acordos entre os serviços de broadcast e os estúdios de cinema e, depois, a serem produzidos e distribuídos pelos próprios canais, através do formato de telefilme. Esse processo ainda se completaria com o surgimento do home video, depois dos canais segmentados de televisão a cabo até chegar nos serviços de Video on Demand hoje tão centrais para a cultura audiovisual. A televisão, portanto, por seu caráter doméstico, cotidiano, trivial, serializado, estaria para sempre detida nos limites estreitos de uma fruição espectatorial dispersiva, ainda que os filmes, redimensionados para a tela pequena, tenham entrado na vida ordinária do lar e nela fincado raízes fundas de circulação e consumo.

Por isso, sempre foi importante para a crítica de cinema, embora este nunca tenha perdido do seu horizonte a matriz de espetáculo popular que lhe marca a origem, reafirmar a sua distinção enquanto meio com linguagem e ambições artísticas próprias, ligadas a uma origem perceptual, a uma gênese a partir da
${ }^{5}$ No original: "In reality, television has never become a completely domesticated medium, or a totally domesticated and domestic material object, however much an affirmation of this kind clashes with common sense (including the common sense that is scientifically credited). Not merely because its presence, even though it has become part of the geography of inhabited space, continues to cause alarm, suspicion and the surveillance kept for things that one knows cannot entirely be trusted (and again, nothing like that happens with fridges or dishwashers); but also because television sets and screens have never in fact abandoned the public spaces that they originally occupied; rather, they have continued to spread exponentially in areas outside the home during and after the phase of domestication". 
${ }^{6}$ No original: "Cinema offers a large-scale, highly detailed and photographic image to a spectator who is engaged in an activity of intense and relatively sustained attention to it. Broadcast TV offers a small image of low definition, to which sound is crucial in holding the spectator's attention. The spectator glances rather than gazes at the screen; attention is sporadic rather than sustained. These forms of attention enable different modes of narration to develop in each medium".

qual se desdobram todas as outras formas audiovisuais. Definir-se dentro de um dispositivo estruturado para a imersão e a contemplação, sem a possibilidade de dispersões externas, numa sessão pública voltada exclusivamente a esse propósito, contribuiu sem dúvidas para esse processo.

Conforme explica John Ellis (1982), a ênfase do cinema no "olhar atento" (que ele chama de gaze) foi crucial para a produção de efeitos estéticos específicos, bem como para a criação de desenvolvimentos técnicos consequentes. Esse "olhar atento" implica usos da imagem e do som próprios, capazes de acionar relações - de adição, de colisão, de esgarçamento etc. - altamente multissensoriais. À televisão, por outro lado, não convinha esse "olhar atento", mas um "olhar de relance" (glance, segundo Ellis), tendo em vista a sua estrutura espectatorial doméstica, a sua linguagem serializada e em fluxo, o seu uso redundante de imagem e som, para evitar a dispersão.

O cinema oferece uma imagem fotográfica em larga escala, altamente detalhada, para um espectador que está engajado em uma atividade de atenção intensa e concentrada. A televisão aberta oferece uma imagem pequena, em baixa definição, para a qual o som é fundamental para manter a atenção do público. O espectador, aqui, olha de relance, ao invés de atento, para a tela; a atenção, portanto, é mais esporádica que concentrada. Essas duas formas de atenção possibilitam modos diferentes de narrativa para cada meio 6 . (Ellis, 1982, pp. 24-25)

O conflito entre gaze e glance se arraigou fundo no debate entre cinema e televisão, sendo recorrente em boa parte das críticas às séries televisivas, como a de Lucrecia Martel, por exemplo. Muitos cobram da televisão e das séries ficcionais uma ênfase estética no gaze, desconsiderando a própria natureza técnica dos modos de produção, distribuição e consumo televisivos. A despeito disso, as mudanças recentes de ordem técnica na produção (sofisticação das câmeras, captadores de áudio e mesas de edição digital), na distribuição (dentro e fora do fluxo televisivo tradicional) e no consumo (televisores gigantes de tela plana, com altíssima qualidade de som e imagem) têm permitido aos diretores de televisão explorar ainda mais o uso expressivo da forma audiovisual, sofisticando as potencialidades da sua linguagem.

Nesse sentido, o desenvolvimento tecnológico de ponta a ponta na produção de imagens televisivas, que hoje faz parte do cotidiano da experiência espectatorial, oferece condições materiais para o aprimoramento das possibilidades estilísticas da televisão num cenário de intensa competitividade global por conteúdo seriado. A mesma questão se estende, por exemplo, ao som, mas em outros termos. É curioso perceber como o livro de Ellis (1982), do início dos anos 1980, quando as formas de transmissão e recepção televisivas eram ainda 
precárias e, em larga medida, compostas apenas de sinal aberto, já apontava para as diferenças entre cinema e televisão sem se apoiar numa hierarquia apriorística, calcada sobremaneira em aspectos técnicos e narrativos que supusessem uma superioridade do filme em relação à ficção seriada. Para continuar no exemplo do som televisivo, é importante perceber como pesquisas mais recentes, a partir de diferentes abordagens, têm endereçado as especificidades materiais da produção, da circulação e da recepção televisivas no que se refere ao tratamento do material audiovisual (Baade \& Deaville, 2016; Carreiro, 2019; Edgar, 2017), destacando como a banda sonora tem funções específicas no meio dispersivo e, a partir delas, pode experimentar novos desdobramentos estéticos e sensórios.

O som pode ser ouvido onde a tela da TV não pode ser vista. Então, o som é usado para garantir certo nível de atenção, para atrair os espectadores de volta a olhar para a tela. Por isso, a importância dos anúncios, das chamadas de abertura e, até mesmo, da música em diferentes formas de séries. $\mathrm{O}$ som segura a atenção de modo mais consistente que a imagem, e oferece uma continuidade que se mantém mesmo diante de lapsos momentâneos de atenção. O resultado disso é um balanço levemente diverso entre som e imagem no comparativo com o cinema. Ao cinema é garantida uma centralidade do espectador por causa do arranjo das poltronas das salas de exibição e do hábito de visionamento de filmes. O som, então, segue a imagem ou diverge dela. A imagem é a referência central no cinema. Mas para a televisão, o som tem um papel muito mais importante ${ }^{7}$. (Ellis, 1982, pp. 128-129)

Observar, portanto, essas diferenças da experiência espectatorial entre filmes e séries sem considerar a natureza dos meios, o histórico de suas distinções e, sobretudo, o estado contemporâneo das formas audiovisuais, apenas reforça o fosso divergente em que cinema e televisão se entrincheiraram. No caso das séries televisivas, não são poucos os exemplos recentes de obras que mantêm o papel apelativo do som, sua reiteração imagética e mesmo a dominância do diálogo na equalização das faixas, para construir também atmosferas - a francesa L'Enffondrement (Desjardins et al., 2019) e a islandesa Ófcerð (Kjartansson, 2015-presente) são ótimos exemplos -; trilhas dissociativas e experimentais - a alemã Dark (Müsch et al., 2017-2020), a estadunidense The Leftovers (Lindelof et al., 2014-2017) e a terceira temporada de Twin Peaks (Frost et al., 1990-1991, 2017) -; e pontos de escuta subjetivados, em auricularização primária - de Breaking Bad (Gilligan et al., 2008-2013) a Atlanta (Glover et al., 2016-presente). A qualidade dos televisores, o convite narrativo ao espectador atento e a lógica criativa por trás da produção seriada contemporânea são indícios que apontam para o desenvolvimento de obras televisivas que, ao invés do
${ }^{7}$ No original: "Sound can be heard where the screen cannot be seen. So sound is used to ensure a certain level of attention, to drag viewers back to looking at the set. Hence the importance of programme announcements and signature tunes and, to some extent, of music in various kinds of series. Sound holds attention more consistently than image, and provides a continuity that holds across momentary lapses of attention. The result is a slightly different balance between sound and image from that which is characteristic of cinema. Cinema is guaranteed a centered viewer by the physical arrangement of cinema seats and customs of film viewing. Sound therefore follows the image or diverges from it. The image is the central reference in cinema. But for $\mathrm{TV}$, sound has a more centrally defining role". 
recuo distintivo, parecem apontar com passadas largas para a constituição artística de um campo de aproximações inevitáveis.

\section{ESTILO E NARRATIVA: ATRAVESSAMENTOS E DISTENSÕES ENTRE FILME E SÉRIE}

Na referida entrevista para o periódico Perfil, Lucrecia Martel aprofunda a sua crítica às séries contemporâneas a partir do comparativo entre as formas narrativas de televisão e cinema:

Há possibilidades [narrativas] a que estava chegando o cinema, e as séries ocuparam o consumo de cinema de autor e o que isso significava na cultura, em termos de trocas. São narrativas muito conservadoras, e com uma dinâmica de televisão, de diálogos

${ }^{8}$ No original: "Hay unas posibilidades a las que estaba llegando el cine, que las series han ocupado el consumo del cine de autor y lo que eso significaba en la cultura, en términos de intercambio. Son narrativas muy conservadoras, y con una dinámica de televisión, de los diálogos cargados de información, mucho mejor hecha". carregados de informação, por melhores que sejam . (Domínguez, 2018, para. 5)

Voltamos, aqui, para o cerne de uma distinção propriamente ontológica: um meio imersivo (o cinema) e um meio dispersivo (a televisão), se vistos em comparação, vão inevitavelmente recorrer a procedimentos narrativos diversos, de modo a atender à captura do engajamento espectatorial, da atenção ao fluxo informacional e, claro, à articulação sequencial dos eventos narrados nas suas lógicas de enunciação unitária (nos filmes) e serializada (nas séries).

Diálogos expositivos, muitas vezes endereçados diretamente ao espectador como os que Martel critica -, são na verdade fundamentais para a compreensão dos eventos narrativos em dispositivos dispersivos. Mesmo séries usualmente celebradas pela sofisticação de seus modelos narrativos recorrem a estratégias repetitivas, reiterativas, recapitulativas e redundantes (Zanetti, 2009) para engajar os espectadores nas histórias - sobre isso, vale lembrar as análises de The Wire (Simon et al., 2002-2008) e Breaking Bad (Gilligan et al., 2008-2013), sobretudo na ênfase que dão para a investigação das lógicas de serialização e suas relações com as matrizes genéricas do melodrama televisivo (Araújo, 2015; Williams, 2014).

Nesse sentido, é importante perceber como as formas narrativas serializadas estão relacionadas às possibilidades de acesso à história permitidas ao espectador, hoje altamente conectado e capaz de manusear a obra audiovisual em variados dispositivos digitais. Se o cinema pode prescindir de sobreposições entre imagem e diálogo, trabalhando com uma imersão mais sensória na narrativa, dentro de uma dramaturgia unitária e ininterrupta, a televisão necessita de, constantemente, chamar a atenção do espectador, interpelá-lo para imergir na história e mesmo permitir que situações móveis de consumo multitela não representem suspensão do engajamento narrativo. Ou seja, as séries televisivas precisam constantemente se 
endereçar ao espectador, recuperá-lo da dispersão inexorável, reconduzi-lo enfim ao encadeamento narrativo de onde ele pode eventualmente ter descarrilhado. Para isso, recorrem a inúmeras estratégias de estilo e narrativa. Algumas já se consolidaram na linguagem comum do fluxo televisivo - como as chamadas de abertura ou os enxertos recapitulativos (no modelo previously on). Outras, porém, são utilizadas com engenho e inventividade, muitas vezes rompendo com a lógica transparente da narração televisiva clássica (Thompson, 2003) e exigindo, portanto, um olhar mais atento à dinâmica narrativa proposta para que se possa, ao cabo, discernir as tradições e as rupturas na linguagem televisual.

Por isso, não é de se estranhar o quanto Lucrecia Martel, mais adiante em sua entrevista, tece comparações no campo das séries televisivas e, em seguida, entre este e o cinema, com o intuito de problematizar as possibilidades narrativas empregadas. Assim segue: "Não se pode comparar House of Cards [Fincher et al., 2013-2018] com CHiPs [Rosner, 1977-1983]. Mas se as compara com as possibilidades a que estava chegando o cinema, a complexidade narrativo-audiovisual, [as séries] são um passo atrás"9 (Domínguez, 2018, para. 5). É fundamental estabelecer aqui os pressupostos da comparação presumida.

Inicialmente, Martel estabelece um recorte dentro do campo das séries televisivas, operando uma hierarquia entre obras de gêneros, formatos, modelos de distribuição e épocas diferentes para, com isso, indicar uma hierarquia evolutiva em curso. A citada CHiPs era um drama policial, de natureza procedural, centrado em uma dupla de policiais rodoviários que, em motocicletas, tentava solucionar os crimes que se apresentavam, se desenvolviam e se resolviam a cada episódio. A série foi exibida pela NBC entre 1977 e 1983, numa época em que os modelos seriados da televisão estadunidense estavam em transição, tanto pela entrada de produtoras independentes na criação de conteúdo original, quanto pelas mudanças regulatórias em termos temáticos e sociais (Feuer et al., 1985; McCabe \& Akass, 2007; Thompson, 1997).

House of Cards (Fincher et al., 2013-2018), por outro lado, é uma série dramática produzida em 2013 pela Netflix, serviço de video on demand (VoD) que iniciou a produção e a oferta de conteúdo original por streaming, ainda no início dos anos 2010 e, com isso, indicou o caminho da economia criativa do audiovisual contemporâneo que, a partir de 2019, contou com a entrada de grandes players do mercado do entretenimento nessa lógica digital de consumo seriado (Bianchini, 2018; Jenner, 2018). Desenvolvida por Beau Willimon, um dramaturgo de renome ${ }^{10}$, a partir de uma série britânica homônima, House of Cards se tornou rapidamente um sucesso, garantido em larga medida pela qualidade da dramaturgia que encenava os interstícios da política americana, e pela força das atuações, tanto de seus protagonistas - Kevin Spacey como Frank
${ }^{9}$ No original: "No podés comparar House of Cards con $\mathrm{CHiPs}$, ponele. Pero si comparás con las posibilidades a las que estaba llegando el cine, la complejidad narrativaaudiovisual, es un paso para atrás".

${ }^{10}$ Sua peça Farragut North foi adaptada para o cinema em 2011, agora com o nome de The Ides of March (Clooney, 2011), e rendeu a Willimon, Grant Heslov e George Clooney (que também dirige o filme) uma indicação ao Oscar de roteiro adaptado. 
Underwood e Robin Wright como Claire Underwood -, quanto de seus coadjuvantes - o destaque é, certamente, para Mahershala Ali, como Remy Danton.

Essa associação entre uma representação shakespeariana da dinâmica política dos Estados Unidos e uma atualidade da crise da democracia ao redor do mundo, que viu em House of Cards um espelho para as suas fraturas institucionais, ajudam a explicar a importância da série como fenômeno cultural dos anos 2010 (Jones \& Soderlund, 2017; Palmen et al., 2018; Reichman, 2017). Mesmo com a derrocada do seu ator principal, afastado da série após acusações de abuso sexual sobre atores mais jovens, a relevância de House of Cards como marco da guinada produtiva em direção aos serviços de VoD e como obra seriada cuja narrativa deve ser urdida, considerando a nova dinâmica de consumo sequencial (o chamado binge watching), permanece bem determinada.

Mas a série da Netflix parece ser um ponto de inflexão dentro de uma trajetória bastante singular de sofisticação da forma narrativa e do estilo audiovisual das ficções seriadas. Não são poucos os estudos que apontam, nos últimos vinte anos, para uma profunda transformação na lógica narrativa das séries televisivas, rompendo com a padronização excessiva dos formatos seriados (unitários, antológicos ou folhetinescos) e produzindo, assim, inovações reconhecíveis na tradição da narrativa televisual (Bucaria \& Barra, 2016; Harlap, 2017; Nahs \& Wheleham, 2017; Ryan \& Thon, 2014; Weinstock \& Spooner, 2016). Quando consideramos a forma narrativa, os conceitos de complexidade narrativa (Mittell, 2006, 2015) e de drama seriado contemporâneo (Silva, 2014, 2016) ajudam a compreender o modo como o storytelling televisivo se tornou um campo vasto de experimentações estéticas, introduzindo formas de contar histórias até então circunstanciais na tradição televisiva. Para tanto, vale observar diacronicamente a própria noção de complexidade narrativa, entendida como "um novo modelo de contar histórias que emergiu com uma alternativa às formas convencionais episódicas ou serializadas que caracterizaram boa parte da televisão americana desde a sua gênese"11 (Mittell, 2015, p. 17).

Em termos poéticos, a complexidade narrativa dá conta de uma construção

${ }^{11}$ No original: "a new model of storytelling has emerged as an alternative to the conventional episodic and serial forms that have typified most American television since its inception". tensa entre a natureza unitária do episódio e o arco longo da narrativa serializada, de modo que o próprio engajamento espectatorial com as histórias tende a se alterar, exigindo assim um mergulho mais profundo nos universos ficcionais, agora eles mesmos habitados por personagens ambíguos e fios narrativos entrelaçados. A concatenação narrativa não progride necessariamente de modo linear e, com isso, a coerência interna da história muitas vezes só se completa com mais de uma assistência. Sobre isso, é curioso como o próprio Mittell (2015) vai recorrer a uma comparação com o cinema estadunidense para destacar as qualidades que as séries complexas possuem e pelas quais serão reconhecidas no porvir. 
Como a Hollywood dos anos 1970 é relembrada muito mais pelo trabalho inovador de Altman, Scorsese e Coppola, que pelos filmes de desastre, romances e comédias mais convencionais (e, em geral, mais populares) que enchiam as salas de cinema, eu acredito que a televisão americana das duas últimas décadas será relembrada como uma época de experimentação e inovação narrativas, que desafiaram as regras do que a mídia poderia fazer ${ }^{12}$. (Mittell, 2015, p. 31)

Uma lista de obras complexas seria inevitavelmente robusta e excludente, dada a quantidade de produções, e mesmo pernóstica, como se objetivasse contrapor os argumentos de Martel, atribuindo, por si, outras lógicas de distinção e validação crítica. Não é nosso objetivo reforçar uma tese distintiva de que a complexidade narrativa opera uma cisão epistêmica na tradição das narrativas televisuais. No entanto, cabe apontar que boa parte dos preconceitos distintivos entre filmes e séries se dá pela articulação entre os pressupostos estéticos da obra unitária clássica e um conhecimento apenas superficial das possibilidades e tradições da narrativa ficcional televisiva.

O mesmo se dá com a questão do estilo audiovisual. Embora tenham, há muito, estabelecido como instância criativa central a figura do escritor/produtor, também conhecido como showrunner, as séries televisivas têm encontrado possibilidades materiais e lógicas produtivas que permitem a exploração da textura auditivo-imagética da televisão pelos diretores, de modo a construir possibilidades expressivas para além da transparência clássica e da redundância entre texto e imagem. No caso das possibilidades materiais, estamos falando da supramencionada sofisticação dos equipamentos de captação, edição e transmissão digital, em alta definição, das informações televisuais. Isso tem permitido que os diretores de televisão possam investir em novas possibilidades expressivas para os sons e as imagens das séries televisivas, que agora, num cenário em que as lógicas produtivas lidam com a intensa disputa comercial entre canais abertos, fechados e serviços de $\mathrm{VoD}$, precisam se dedicar à criação de obras singulares tanto em narrativa quanto em estilo.

Isso implica, inclusive, diretores de televisão renomados no comando criativo das séries, numa tradição que remonta a diretores de cinema célebres que trabalharam em minisséries e especiais televisivos - como Ingmar Bergman, Jean-Luc Godard, Rainer Werner Fassbinder, Krysztof Kieslowski - e que hoje têm como epítome o papel de David Lynch em Twin Peaks (Frost et al., 19901991, 2017), mas que também se espraia por nomes como Martin Scorsese: Boardwalk Empire (Winter et al., 2010-2014), Vinyl (Scorsese et al., 2016), David Fincher: House of Cards (Fincher et al., 2013-2018), Mindhunter (Kono et al., 2017-2019), Jane Campion: Top of the Lake (Sherman et al., 2013-2017),
${ }^{12}$ No original: "Yet just as 1970s Hollywood is remembered far more for the innovative work of Altman, Scorsese, and Coppola than for the more commonplace (and often more popular) conventional disaster films, romances, and comedies that filled theaters, I believe that American television of the past 20 years will be remembered as an era of narrative experimentation and innovation, challenging the norms of what the medium can do". 
Steven Soderbergh: The Knick (Jacobs et al., 2014-2015), Mosaic (Silver, 2018), Ava DuVernay: Queen Sugar (DuVernay et al., 2016-presente), When They See Us (Skoll et al., 2019), Woody Allen: Crisis in Six Scenes (Aronson, 2016), Bruno Dumont: P'tit Quinquin (Dumont, 2014), Sussane Bier: The Night Manager (Farr et al., 2016) e Spike Lee: She's Gotta Have It (Lee, 2017-2019).

Novamente, o elenco de referências possíveis é apenas circunstancial e aponta, ao cabo, para um horizonte ainda pouco explorado, em termos analíticos, de obras audiovisuais cujo estilo precisa ser compreendido para além das comparações hierárquicas pouco justificadas. Não bastasse isso, acreditamos ainda que a criação de estilos televisivos não é resultado apenas da incorporação de autores renomados do campo cinematográfico para o fazer televisual, no sentido de uma dependência valorativa de um campo em relação a outro. O que nos interessa aqui, precisamente, são essas interconexões, que põem em perspectiva o discurso distintivo habitual diante de experiências e experimentações muito singulares na história da televisão.

Em termos teóricos, dois conceitos têm nos ajudado bastante a compreender as especificidades do audiovisual televisivo: de um lado, a exploração do próprio conceito de estilo para a televisão (Butler, 2010) e, de outro lado, o retorno ao conceito de televisualidade, como um operador próprio para a análise das ficções seriadas. John Caldwell (1995), em trabalho seminal, defende que a televisualidade é a forma específica através da qual a televisão - da mais popular à mais erudita - produz e performatiza o estilo, aqui entendido mais em sua dimensão decorativa e apelativa, que na lógica dos padrões históricos e dos esquemas autorais.

Com crescente frequência, o estilo se tornou ele mesmo o sujeito, o significado, se preferes, da televisão. De fato, essa autoconsciência do estilo se tornou tão grande que ela pode ser melhor caracterizada como uma atividade, uma performance do estilo, ao invés do que apenas um olhar específico.... Em suma, estilo, há muito visto como um mero significante ou um recipiente para o conteúdo, os temas, as ideias, tornou-se ele mesmo um dos significados televisivos mais privilegiados ${ }^{13}$. (Caldwell, 1995, p. 5) the subject, the signified, if you will, of television. In fact, this self-consciousness of style became so great that it can more accurately be described as an activity, as a performance of style, rather than as a particular look. ... In short, style, long seen as a mere signifier and vessel for content, issues, and ideas, has now itself become one of television's most privileged and showcased signifieds".
Para garantir, portanto, a manutenção do espectador no programa, dentro de um dispositivo técnico de zapping ou sociabilização digital dispersiva, a televisão recorre a formas seriadas, com narrativas e estilos, cujas matrizes históricas a precedem, mas que nela - na televisão - parecem ter encontrado um meio determinante para a sua perpetuação continuada. A serialização, portanto, não é um mero imperativo comercial, alicerçado em propósitos escusos de proliferação exaustiva, mas uma maneira técnico-estética tanto de organização dos 
conteúdos, quanto de engajamento sensório e afetivo das audiências. Por isso, a exploração dos aspectos narrativos e estilísticos fazem parte da rotina criativa de autores e diretores que, cada vez mais, parecem encontrar nas obras seriadas um campo de experimentação ainda vasto a ser desbravado.

\section{CONSIDERAÇÕES FINAIS}

Para além das comparações espectatoriais, estilísticas e narrativas, a relação entre cinema e televisão se enlaça também nos modelos de negócio próprios a cada meio, mas que, a partir sobretudo da segunda metade do pós-guerra, tornaram-se cada vez mais imbricados. Por modelo de negócio, entendemos as diferentes maneiras pelas quais os meios se organizam para permitir a estrutura de produção, distribuição e consumo dos seus produtos. Aqui, cinema e televisão muitas vezes se diferenciam, mas para logo em seguida se reencontrarem. Dentro de um cenário multitela que demanda circulação das obras em diferentes janelas, a experiência da sala de exibição não limita o cinema a esse espaço dominante, mas se estabelece como janela inicial de apreciação. Não bastasse isso, tanto os grandes estúdios, hoje fortalecidos em conglomerados midiáticos, quanto as produtoras independentes necessitam cada vez mais produzir também para a televisão e os serviços de streaming, seja por causa de leis de cota de tela (como a lei 12.485/11, no Brasil), seja pela alta demanda de conteúdo dos diferentes exibidores, trazendo para o horizonte das disputas econômicas as tensões entre cinema e televisão.

Para se ter uma ideia - e aqui trago dados disponibilizados pela Agência Nacional do Cinema (Ancine, 2018) -, entre 2011 e 2016, 701 filmes foram lançados comercialmente no Brasil, tendo o cinema como janela prioritária de exibição. Desses, apenas 64 não foram depois lançados em outros seguimentos. Os demais tiveram como segunda janela a TV aberta (quinze), a TV Paga (241), serviços de $\mathrm{VoD}$ (163) e vídeo doméstico (218). Além disso, desse total de 637 filmes, 515 tiveram uma terceira janela, 266 uma quarta e, por fim, 101 tiveram até uma quinta janela de exibição.

Pensar, portanto, o cinema e a televisão enquanto meios díspares, hierarquicamente distintos, não condiz com o que é produzir audiovisual no Brasil e no mundo hoje. Suas estratégias, suas linguagens e seus dispositivos podem sempre apontar para usos diversos do texto audiovisual - e é bom que o façam. Porém, e esse é o argumento que defendo aqui, compreender as complexas dinâmicas que aproximam - estética, econômica e culturalmente - a televisão do cinema deve ser uma importante matriz discursiva - e inclusive, política - do que é e será produzir e refletir sobre audiovisual hoje. Epistemologicamente, parece determinante inserir o debate sobre as séries televisivas contemporâneas, precisamente 
nessa intersecção nebulosa dos campos de estudos de cinema e de televisão, em que alguns veem as evidências de um elitismo cultural, mas outros enxergam as dinâmicas do entrelaçamento midiático das audiovisualidades contemporâneas.

Em termos metodológicos, é importante ainda apontar caminhos que desatem os nós desses preconceitos, de modo a compreender os casos particulares na historicidade de suas manifestações e, a partir disso, urdir as eventuais generalizações que definem os processos de modo mais amplo. Essa articulação entre indução e dedução constitui etapa indispensável para a ruptura com os solipsismos da crítica cultural mais enviesada, de modo que o lugar das séries televisivas na tradição das formas audiovisuais possa ser compreendido com a complexidade que lhe é própria.

Newman e Levine (2012) nos lembram que o processo de legitimação da televisão, seja na academia, seja na crítica cultural, é um movimento sem fim, que precisa sempre ser reforçado, debatido, disputado. Não se trata apenas de uma delimitação distintiva de um campo que precisa ser apreciado a contento, mas de um esforço para compreender a história cultural dos meios, as transformações poéticas e estéticas das obras e, por fim, as dinâmicas autorais que configuram a singularidade da produção seriada e sua aguda incidência no cenário cultural contemporâneo. A serialização, portanto, não pode representar um passo atrás - como se, ao cabo, o desenvolvimento da linguagem fosse uma evolução retilínea conduzida, é óbvio, pelo cinema autoral -, mas certamente é um passo além, um caminho de possibilidades expressivas alicerçado numa estrada cada vez mais comum de aproximações intermidiáticas.

Ao analisar diacronicamente os processos discursivos de distinção entre filmes e séries, estabelecemos neste artigo três eixos centrais que alicerçaram o debate: espectorialidade, estilística e narrativa. Como já argumentamos, esses eixos não esgotam a questão, visto que outros elementos, dentro das condições históricas de produção, circulação e consumo de cada meio específico, podem ser recuperados para ilustrar o problema. Ao revisitar a literatura sobre o tema, porém, parece claro que essa distinção atravessa não apenas os pontos de vista das instâncias produtivas, como o caso da cineasta Lucrecia Martel, mas também a crítica cultural, o consumo e a própria academia, numa dinâmica discursiva que apresenta especificidades próprias em cada país, mas que, no Brasil, se manifesta numa dificuldade perene em pensar os campos de estudos de televisão e de estudos de cinema como áreas muito mais transversalmente articuladas do que as nossas agendas de pesquisa pressupõem.

O que advogamos aqui, ao cabo, é que esse esforço distintivo deve ser criticado com base nos efeitos problemáticos que impõe à compreensão efetiva das formas contemporâneas de produção, circulação e consumo de audiovisual. Com a pandemia de Covid-19, o fechamento de sets de filmagem, estúdios de 
televisão, salas e festivais de cinema, além do fortalecimento dos serviços de streaming na produção de conteúdos originais e na distribuição de uma programação diversa, doméstica e tecnologicamente acessível, pensar o campo do audiovisual nessa articulação entre cinema, televisão, internet e mídias interativas, parece um caminho inescapável para o entendimento de um presente em profunda transformação e de um futuro que se antecipa radicalmente. $\mathbf{M}$

\section{REFERÊNCIAS}

Agência Nacional do Cinema. (2018). Filmes brasileiros: Causa ou efeito. o cenário em 2018 e as perspectivas para 2019. https://bit.ly/3vV6XWI

Andrews, H. (2014). Television and British cinema: Convergence and divergence since 1990. Palgrave McMillan.

Araújo, J. (2015). Crystal blue persuasion: A construção do mundo ficcional no seriado televisivo Breaking Bad [Dissertação de mestrado, Universidade Federal da Bahia]. Repositório institucional da UFBA. https://bit.ly/3fGZDII

Aronson, E. (Produtora executiva). (2016). Crisis in six scenes [Crise em seis cenas] [Série de televisão]. Amazon Studios; Gravier Productions.

Aumont, J. (2011). Que reste-t-il du cinéma? Rivista di estética, (46), 17-31. https://doi.org/10.4000/estetica.1634

Baade, C. L., \& Deaville, J. (2016). Music and the broadcast experience: Performance, production and audiences. Oxford University Press.

Bahia, L. (2014). A telona e a telinha: Encontros e desencontros entre cinema e televisão no Brasil [Tese de doutorado, Universidade Federal Fluminense]. Repositório do Programa de Pós-Graduação em Comunicação da UFF. https://bit.ly/2S7V7tI

Bahia, L., \& Amancio, T. (2010). Notas sobre a emergência de um novo cenário audiovisual no Brasil nos anos 2000. Contracampo, (21), 113-130. https:// doi.org/10.22409/contracampo.v0i21.41

Balogh, A. M. (2002). O discurso ficcional na TV: Sedução e sonho em doses homeopáticas. Edusp.

Bianchini, M. (2018). A Netflix no campo de produção de séries televisivas e a construção narrativa de Arrested Development [Tese de doutorado, Universidade Federal da Bahia]. Repositório institucional da UFBA. https://bit.ly/3wQljYD

Bourdieu, P. (1996). As regras da arte: Gênese e estrutura do campo literário. Companhia das Letras.

Bourdieu, P. (2007). A distinção: Crítica social do julgamento. Edusp; Zouk.

Bucaria, C., Barra, L. (2016). Taboo comedy: Television and controversial humour. Palgrave MacMillan. 
Buonanno, M. (2008). The age of television: Experiences and theories. Intellect Books. Butler, J. G. (2010). Television style. Routledge.

Butler, J. G. (2018). Television: Visual storytelling and screen culture. Routledge. Calabrese, O. (1984). Los replicantes. Anàlisi, (9), 71-90. https://bit.ly/2S3LgVN Caldwell, J. T. (1995). Televisuality: Style, crisis and authority in American television. Rutgers University Press.

Carreiro, R. (2019). Além da muralha: Continuidade intensificada no som de Game of Thrones. In A. Caminos, A. S. Médola, \& A. Suing (Eds.), A nova televisão: Do Youtube ao Netflix (pp. 238-260). Ria Editorial.

Clooney, G. (Diretor). (2011). The ides of March [Filme]. Columbia Pictures; Smokehouse Pictures; Appian Way Productions; Exclusive Media; Cross Creek Pictures.

Desjardins, G., Bernard, J., \& Ughetto, B. (Criadores). (2019). L'Enffondrement [O colapso] [Série de televisão]. Canal +; ET BIM Distribution.

Domínguez, J. M. (2017, 29 de setembro). Lucrecia Martel: "Las series son un paso atrás". Perfil. https://bit.ly/3i9AyI1

Dumont, B. (Diretor). (2014). P'tit Quinquin [O pequeno Quinquin] [Filme/ Série de televisão]. ARTE France; 3B Productions; Pictanovo Région NordPas-de-Calais; Scope Pictures; Cofinova 10.

DuVernay, A., Carter, M., \& Winfrey, O. (Produtoras executivas). (2016-presente). Queen Sugar [Série de televisão]. Warner Horizon Television; Harpo Films; Forward Movement; Array Filmworks (Temporada 4).

Edgar, A. N. (2017). Subordinating sound to screen: Television music supervision in an imagocentric world. Sound Studies: An Interdisciplinary Journal, 3(2), 49-63. https://doi.org/10.1080/20551940.2017.1361270

Edgerton, G. R., \& Rose, B. G. (2005). Thinking outside the box: A contemporary television genre reader. University Press of Kentucky.

Ellis, J. (1982). Visibles fictions: Cinema: Television: Video. Routledge.

Farr, D., Bier, S., le Carré, J., Hiddleston, T., \& Laurie, H. (Produtores executivos). (2016). The night manager [O gerente noturno] [Série de televisão]. The Ink Factory; Demarest Films.

Feuer, J., Kerr, P., \& Vahimagi, T. (1985). MTM: Quality television. British Film Institute. Fincher, D., Spacey, K., Roth, E., Donen, J., Brunetti, D., Davies, A., Dobbs, M., Melfi, J., Willimon, B., Manson, D., Coles, J. D., \& Wright, R. (Produtores executivos). (2013-2018). House of cards [Série de televisão]. Media Rights Capital; Trigger Street Productions; Wade/Thomas Productions; Knight Takes King Productions.

Fresco, A. (2019). Cannes vs. Netflix: El cine, desde la pantalla grande hacia la “softwareización". In A. Caminos, A. S. Médola, \& A Suing (Eds.), A nova televisão: Do YouTube ao Netflix (pp. 261-273). Ria Editorial. 
Frost, M., Lynch, D., \& Sutherland, S. S. (1990-1991, 2017). Twin peaks [Série de televisão]. Lynch/Frost Productions; Propaganda Films; Spelling Television; Twin Peaks Productions; Showtime (apenas temporada 3); Rancho Rosa Partnership (apenas temporada 3).

Gilligan, V., Johnson, M., \& MacLaren, M. (Produtores executivos). (2008-2013). Breaking Bad [Série de televisão]. High Bridge Entertainment; Gran Via Productions; Sony Pictures Television.

Glover, D., Simms, P., McGunigle, D., Glover, S., \& Murai, H. (Produtores executivos). (2016-presente). Atlanta [Série de televisão]. 343 Incorporated; MGMT. Entertainment; FXP.

Gregorie, G. (1987). Le nouveau paysage audiovisuel, un gentlemen's agreement. CinémAction, (44), 35-43.

Harlap, I. (2017). Television drama in Israel: Identities in post-TV cultures. Bloomsbury Academic.

Hart, J. A. (2004). Technology, television and competition: The politics of digital $T V$. Cambridge University Press.

Hennebelle, G., \& Prédal, R. (Eds.). (1987). L'influence de la télévision sur le cinema. CinémAction, (44).

Jacobs, G., Soderbergh, S., Amiel, J., Begler, M., Sugar, M., \& Owen, C. (Produtores executivos). (2014-2015). The Knick [Série de televisão]. AMBEG Screen Products; Anonymous Content; Extension 765.

Jenner, M. (2018) Netflix and the re-invention of television. Palgrave MacMillan. Jones, P., \& Soderlund, G. (2017). The conspirational mode in American television: Politics, public relations and journalism in House of Cards and Scandal. American Quartely, 69(4), 833-856. https://doi.org/10.1353/aq.2017.0069

Kjartansson, S. (Produtor executivo). (2015-presente). Ófærð [Trapped]. RVK Studios. Kono, B., Theron, C., Penhall, J., Chaffin, C., Donen, J., Fincher, D., \& Miles, C. (Produtores executivos). (2017-2019). Mindhunter [Série de televisão]. Denver and Delilah Productions.

Lee, S. (Produtor executivo). (2017-2019). She's gotta have it [Série de televisão]. 40 Acres \& A Mule Filmworks.

Lindelof, D., Perrotta, T., Berg, P., Aubrey, S., Leder, M., Spezialy, T., \& Kelly, E. (Produtores executivos). (2014-2017). The leftovers [Série de televisão]. White Rabbit Productions; Film 44; Warner Bros. Television; HBO Entertainment. Lobato, R. (2019). Netflix nations: The geography of digital distribution. New York University Press.

Machado, A. (1997). A arte do vídeo. Brasiliense

Machado, A. (2014). A televisão levada a sério. Editora Senac SP. 
Mazdon, L. (1999). Cinema and television: From enmity to interdependence. In M. Scriven \& M. Lecomte (Eds.), Television broadcasting in contemporary France and Britain (pp. 71-82). Berghahn Books.

McCabe, J., Akass, K. (2007). Quality TV: Contemporary American television and beyond. Bloomsburry Academic.

Mendonça Filho, K., \& Dorneles, J. (Diretores). (2019). Bacurau [Filme]. SBS Productions; CinemaScópio; Globo Filmes.

Mittell, J. (2004). Genre and television: From cop shows to cartoons in American culture. Routledge.

Mittell, J. (2006). Narrative complexity in contemporary American television. The Velvet Light Trap, (58), 29-40. https://doi.org/10.1353/vlt.2006.0032

Mittell, J. (2015). Complex TV: The poetics of contemporary television storytelling. New York University Press.

Müsch, J., Friese, J., Berg, Q., Wiedemann, M., \& bo Odar, B. (Produtores executivos). (2017-2020). Dark [Série de televisão]. Wiedemann \& Berg Television.

Nahs, M., \& Wheleham, I. (2017). Reading Lena Dunham's Girls: Feminism, postfeminism, authenticity, and gendered performance in contemporary television. Palgrave MacMillan.

Newman, M., \& Levine, I. (2012). Legitimating television: Media convergence and cultural status. Routledge.

Ortiz, R. (1995). A moderna tradição brasileira. Brasiliense.

Palmen, D., Derksen, J., \& Koltholf, E. (2018). House of Cards: Psycopathy in politics. Public Integrity, 20(5), 427-443. https://doi.org/10.1080/1099992 2.2017.1402736

Ramos, F. P. (2016). Mas afinal, o que sobrou do cinema? A querela dos dispositivos e o eterno retorno do fim. Galáxia, (32), 38-51. https://doi. org/10.1590/1982-25542016225800

Reichman, B. (2017). House of Cards: Shakespearean DNA in the trilogy and the series. Raído, 11(28), 141-164. https://doi.org/10.30612/raido.v11i28.6316

Rosner, R. (Criador). (1977-1983). CHiPs [Série de televisão]. Rosner Television; MGM Television.

Ryan, M. L., \& Thon, J.-N. (2014). Storyworlds across media: Towards a media conscious narratology. University of Nebraska Press.

Scorsese, M., Jagger, M., Winter, T., Pearman, V., Yorn, R., Koskoff, E. M., Melfi, J., Coulter, A., Mastras, G., Burns, S. Z., \& Borenstein, M. (Produtores executivos). (2016). Vinyl [Série de televisão]. Jagged Productions; Sikelia Productions; Cold Front Productions.

Sherman, E., Canning, I., Campion, J., \& Laurenson, J. (Produtores executivos). (2013-2017). Top of the lake [Série de televisão]. See-Saw Films. 
Silva, M. V. B. (2014). Cultura das séries: Forma, contexto e consumo de ficção seriada na contemporaneidade. Galáxia, (27), 241-252. http://dx.doi. org/10.1590/1982-25542014115810

Silva, M. V. B. (2016). Origem do drama seriado contemporâneo. MATRIZes, 9(1), 127-143. https://doi.org/10.11606/issn.1982-8160.v9i1p127-143

Silver, C. (Produtor executivo). (2018). Mosaic [Série de televisão]. Home Box Office (HBO).

Simon, D., Colesberry, R. F., \& Noble, N. K. (Produtores executivos). (20022008). The wire [A escuta] [Série de televisão]. Blown Deadline Productions; HBO Entertainment.

Skoll, J., King, J., Rosenthal, J., De Niro, R., Welsh, B., Winfrey, O., \& DuVernay, A. (Produtores executivos). (2019). When they see us [Olhos que condenam] [Série de televisão]. Tribeca Productions; ARRAY; Participant Media.

Smith, A. N. (2018). Storytelling industries: Narrative production in the $21^{\text {st }}$ century. Palgrave McMillan.

Sociedade Brasileira de Estudos de Cinema e Audiovisual. (s.d.). Mission Statement. https://bit.ly/3ihNa01

Thompson, K. (2003). Storytelling in film and television. Harvard University Press.

Thompson, R. J. (1997). Television's second golden age: From Hill Street Blues to ER. Syracuse University Press.

Weinstock, J. A., \& Spooner, C. (2016). Return to Twin Peaks: New approaches to materiality, theory, and genre on television. Palgrave MacMillan.

Williams, L. (2014). On The Wire. Duke University Press.

Winter, T., Scorsese, M., Wahlberg, M., Van Patten, T., Korder, H., \& Levinson, S. (Produtores executivos). (2010-2014). Boardwalk empire [Boardwalk empire: O império do contrabando] [Série de televisão]. Leverage Entertainment; Closest to the Hole Productions; Sikelia Productions; Cold Front Productions.

Zanetti, D. (2009). Repetição, serialização, narrativa. MATRIZes, 2(2), 181-194. https://doi.org/10.11606/issn.1982-8160.v2i2p181-194

Artigo recebido em 12 de março de 2021 e aprovado em $1^{\circ}$ de junho de 2021. 